\title{
PERFIL DOS CONSELHEIROS LOCAIS DE SAÚDE DO MUNICÍPIO DE JOINVILLE
}

\section{PROFILE OF LOCAL HEALTH COUNSELORS IN THE MUNICIPALITY OF JOINVILLE}

\author{
lara dos Reis Vaichulonis \\ Instituto Federal de Santa Catarina, Campus Joinville, Joinville, SC, Brasil \\ iara.rvaic@gmail.com
}

Fernando de Oliveira Ullirsch

Instituto Federal de Santa Catarina, Campus Joinville, Joinville, SC, Brasil

fernando.ullirsch@gmail.com

Andrea Heidemann

Instituto Federal de Santa Catarina, Campus Joinville, Joinville, SC, Brasil andrea.heimann@ifsc.edu.br

Caroline Orlandi Brilinger Instituto Federal de Santa Catarina, Campus Joinville, Joinville, SC, Brasil caroline.brilinger@ifsc.edu.br

\section{RESUMO}

O presente estudo tem por objetivo descrever o perfil dos conselheiros locais de saúde (CLS) do município de Joinville/SC. Foi realizada uma pesquisa qualiquantitativa do tipo levantamento. O procedimento de coleta de dados utilizado foi um questionário on-line, com perguntas abertas e fechadas em que houve a participação de 71 CLS de um total de 264 . Verificou-se prevalência de CLS do gênero feminino, casados, empregados do setor público, sem experiência na área da saúde e representantes dos usuários (sociedade civil) e do Distrito de Saúde Norte. Os CLS valorizam desse espaço de controle social e veem sua intervenção como relevante para a efetivação do SUS. A avaliação dos respondentes foi positiva quanto ao apoio e a transparência do município no que diz respeito ao apoio técnico, à infraestrutura e ao acesso às informações necessárias para a efetivação da participação e do controle social. A relação com o CMS foi vista como favorável para o fortalecimento do SUS em Joinville. A capacitação dos CLS é percebida como necessária e que requer investimento por parte do poder público. Demandas como o papel dos conselheiros, orçamento público, atuação do Ministério Público e transparência social, foram citadas como possíveis temas em futuras capacitações.

Palavras-chave: Sistema Único de Saúde. Controle Social. Conselhos de Saúde.

\begin{abstract}
This study aims to describe the profile of local health counselors (CLS) in Joinville/SC. A qualiquantitative survey was carried out. The data collection procedure used was an online questionnaire, with open and closed questions in which there was the participation of $71 \mathrm{CLS}$ out of 264. There was a prevalence of CLS of the female gender, married, employees of the public sector, without experience in the health area and representatives of users (civil society) and the Northern Health District. The CLS value this social control space and see its intervention as relevant to the effectiveness of the SUS. The respondents' assessment was positive regarding the support and transparency of the municipality with regard to technical support, infrastructure and access to the information necessary for effective participation and social control. The relationship with the Municipal Health Council was seen as favorable to the strengthening of SUS in Joinville. The training of CLS is perceived as necessary and requires investment by the government. Demands such as the role of councilors, the public budget,
\end{abstract}

Recebido em: 09/11/2021

Aceito para publicação em: 18/12/2021. 
the role of the Public Prosecutor and social transparency, were cited as possible topics in future training.

Keywords: Unified Health System. Social Control. Health Councils.

\section{INTRODUÇÃO}

O exercício do controle social está relacionado diretamente à participação dos cidadãos na gestão pública, ou seja, intervindo na tomada de decisões e fiscalizando a utilização dos recursos públicos para que realmente atendam aos interesses da população. Portanto, o controle social se concretiza no processo de mobilização social de acordo com a capacidade da sociedade civil organizada de interferir na gestão pública (PEDRINI; ADAMS; SILVA, 2007).

A intervenção contínua da sociedade na gestão dos recursos públicos é um direito assegurado na Constituição Federal de 1988. Assim, o cidadão tem na conquista da cidadania o direito de votar para escolher seus representantes e, também, fiscalizar suas ações e os gastos com as políticas públicas.

Um importante seguimento de participação e fiscalização dos recursos públicos são os conselhos municipais de políticas públicas, os quais também contribuem na implantação e na implementação das políticas de saúde em todas as esferas de governo (BRASIL, 2013).

Por sua vez, os conselhos locais de saúde são instâncias colegiadas, de caráter permanente e deliberativo, integrante à unidade de saúde que tem poder de decisão, participação e colaboração efetiva nos programas e ações que são desenvolvidas em cada unidade de saúde fortalecendo assim, a participação social em todos os espaços da política de saúde (BRASIL, 1990). Dessa maneira, os conselhos locais apresentam-se como espaços que permitem o diálogo entre a sociedade civil e o governo, possibilitando o reconhecimento da realidade vivida pelos trabalhadores em saúde, administradores, usuários e a sua relação com o SUS e a rede municipal.

No entanto, Degenszajn (2013) ressalta que não podemos supor que o controle social seja feito apenas por esses canais, pois essa foi uma das formas que os movimentos sociais conseguiram conquistar, mas precisa ser bem acompanhada e avaliada juntando com outras formas de organização e mediação política. Vale ressaltar que o perfil dos conselhos difere entre os municípios, mas a falta de conhecimento sobre o SUS é quase que constante. Esta falta de informação interfere diretamente na atuação desses sujeitos sociais e, desta maneira, é fundamental que o gestor municipal de saúde tenha conhecimento desta realidade para proporcionar capacitações que possibilitem aos conselheiros a vivência da participação social.

Joinville é o município mais populoso de Santa Catarina com cerca de 590.466 habitantes (IBGE, 2020). O Conselho Municipal de Saúde de Joinville foi criado em 1991, funcionando regularmente desde então, e conta com a representação dos conselhos locais em sua composição (JOINVILLE, 2005). Existem 35 conselhos locais de saúde que atuam em diferentes áreas do município e envolvem aproximadamente 264 conselheiros. Para que a assessoria técnica da Secretaria Municipal de Saúde (SMS) de Joinville possa fortalecer esses importantes espaços de controle social é fundamental compreender o perfil desses sujeitos políticos para elaborar propostas que facilitem a participação e o investimento em capacitação permanente.

Nesse encaminhamento, o presente estudo descreve o perfil socioeconômico e político dos conselheiros locais de saúde (CLS) do município de Joinville/SC. Bem como, identifica as percepções dos conselheiros acerca do controle social e aponta possíveis demandas para capacitação dos CLS.

\section{METODOLOGIA}

Esta pesquisa foi formalizada junto à SMS de Joinville e submetida a apreciação ética, conforme parecer $n^{\circ}$ 4.410.456. Trata-se de um levantamento com abordagem qualiquantitativa e objetivos descritivos com foco nos 264 CLS atuantes nos 35 conselhos locais de saúde do município de Joinville/SC.

\begin{tabular}{llllll}
\hline Hygeia Uberlândia - MG & Edição especial: X GeoSaude & Fev./2022 & p. 12-22 & Página & 13
\end{tabular}


A pesquisa foi dividida em cinco etapas. Primeiro, a uma revisão narrativa da literatura a fim de fundamentá-la teoricamente. Segundo, pesquisa documental para identificar os conselhos locais de saúde ativos em Joinville e a quantificação dos seus participantes.

A terceira etapa foi a criação do instrumento de coleta de dados. Considerando a impossibilidade de encontros presenciais com os CLS, em função da pandemia de Covid-19, e visando menor custo, optou-se pelo questionário on-line. A ferramenta Google Forms ${ }^{\circledR}$ foi escolhida por conveniência dos autores para criação e aplicação.

A elaboração das questões foi subsidiada por estudos semelhantes realizados em outros municípios brasileiros (RAMOS et al., 2012; LEMOS et al., 2012). Foram utilizadas questões abertas e fechadas, primando pela simplicidade do linguajar, de modo a ser acessível a todos os participantes. O questionário passou por pré-teste com seis CLS.

A aplicação do questionário, quarta etapa, foi realizada entre novembro e dezembro de 2020. Foram contatados 32 presidentes dos conselhos locais de saúde, explicados os objetivos da pesquisa e distribuídos o link do questionário. Para responder o questionário, os participantes deveriam ler e manifestar aceite do Termo de Consentimento Livre e Esclarecido (TCLE). Por fim, obteve-se a participação de $71 \mathrm{CLS}$, o que corresponde a $26,51 \%$ do universo da pesquisa. O aproveitamento das respostas foi de $100 \%$.

Por fim, para a etapa de análise dos dados, as respostas foram tabuladas no Google Sheet ${ }^{\circledR}$ e analisadas por meio de estatística descritiva e como suporte o referencial teórico deste estudo.

\section{RESULTADOS E DISCUSSÃO}

\section{O perfil sociodemográfico dos CLS de Joinville}

Os conselhos locais de saúde do município de Joinville são organizados em três distritos, Norte, Sul e Centro, de acordo com a distribuição geográfica dos distritos sanitários no município, uma vez que para que ocorra a criação de um conselho local de saúde deverá existir uma ou mais unidades básicas de saúde no território (JOINVILLE, 2005). Os participantes da pesquisa atuam majoritariamente no Distrito de Saúde Norte $(n=42,59,1 \%)$. Do Distrito Sul foram 16 participantes $(22,5 \%)$ e do distrito Centro foram 13 participantes $(18,3 \%)$, totalizando 71 respondentes.

Dentre os participantes da pesquisa, houve uma maior proporção de CLS do gênero feminino ( $\mathrm{n}=41$, $57,7 \%)$ do que do gênero masculino ( $n=30,42,3 \%)$. Quanto à faixa etária, observou-se que os sujeitos da pesquisa têm idades entre 30 e 70 anos, sendo que 45 conselheiros $(65,3 \%)$ possuem entre 40 e 60 anos.

A proporção de gênero observada neste estudo está em consonância com a população brasileira e joinvilense. De acordo com o Instituto Brasileiro de Geografia e Estatística (2020), no Censo 2010, as mulheres representam $51,5 \%$ da população brasileira e $50,3 \%$ da população residente em Joinville. Também demonstra uma certa paridade na participação de homens e mulheres nos conselhos locais de saúde em Joinville. Wollstonecraft (2016) defende a importância das mulheres ocuparem espaços de participação política, ou seja, tomar decisões e discutir leis que garantam seus direitos e de toda a sociedade.

Nota-se a ausência de participação de adultos jovens. No entanto, o predomínio de participantes de idade elevada já era esperado. Conforme Cezare (2009), é necessário considerar que, especialmente os representantes do poder público, são pessoas com cargos de confiança, com experiência para debater junto à sociedade civil as demandas e reivindicações. $E$, no geral, estas são pessoas que se concentram em faixas etárias mais altas.

Avaliando o estado civil, 60 (84,5\%) dos CLS que participaram da pesquisa são casados. Os solteiros representam seis $(8,5 \%)$ dos pesquisados. Viúvos e separados/divorciados são, respectivamente, dois $(2,8 \%)$. Um respondente se enquadrou em "outras opções". Em Porto Alegre/RS, Nahra (2006) verificou que $61,1 \%$ dos CLS eram casados e os solteiros e desquitados/divorciados perfizeram $18,5 \%$ cada.
Hygeia
Uberlândia - MG
Edição especial: X GeoSaude
Fev./2022
p. $12-22$
Página 14 
No tocante à escolaridade, $27(38 \%)$ dos CLS que responderam o questionário afirmam ter pósgraduação, dentre estes, 24 (88\%) eram mulheres. Os conselheiros que declararam possuir ensino superior completo foram $15(21,1 \%)$, enquanto quatro $(5,6 \%)$ possuem este nível de forma incompleta. Quanto ao ensino médio, $15(21,1 \%)$ detêm de forma completa e dois $(2,8 \%)$ de forma incompleta. Conselheiros com ensino fundamental completo e incompleto representam, respectivamente, cinco $(7 \%)$ e três $(4,2 \%)$. A ampla escolaridade dos CLS demonstra uma maior possibilidade de efetiva atuação nos conselhos.

De acordo com Souza, Barros e Oliveira (2007), para que os conselhos se tornem um espaço coletivo tendo atuação plena e democrática, é necessário e importante que os próprios membros dos conselhos tenham uma formação não apenas técnica, mas também política, já que seu trabalho se desenvolve em compreender os direitos de cidadania. E, com esses conhecimentos, se amplia o rompimento das lógicas de tutela e dependência. Diante disso, observa-se a importância da escolaridade de políticas públicas e, entre eles, também, os conselheiros locais de saúde.

Cabe destacar a elevada escolaridade das mulheres em relação aos homens. Beltrão e Alves (2009), consideram que a possível redução do hiato de gênero e a questão do maior acesso das mulheres à educação são consequências de diversas ações promovidas pela Organização das Nações Unidas (ONU), desde os anos 2000, partindo do princípio de que para se chegar a um mundo mais justo e próspero é preciso eliminar as discriminações de gênero em todos os campos de atividade, especialmente na educação, propiciando maior status, autonomia e empoderamento das mulheres.

Quanto à ocupação dos sujeitos da pesquisa, obtivemos 68 respostas, já que três participantes não informaram sua ocupação atual. Diante disso, 26 (38,2\%) são servidores públicos e 23 (33,8 \%) são aposentados, nove (13,2\%) são empregados do setor privado, 6 (8,8\%) são desempregados e quatro (6\%) são autônomos/profissionais liberais. Em Porto Alegre/RS, verificou-se que $36,6 \%$ dos participantes de conselhos eram aposentados (NAHRA, 2006). A predominância dos empregados no setor público e aposentados podem estar relacionados às facilidades para participar das reuniões do CLS. Comumente, os servidores públicos são dispensados sem prejuízos para a participação e os aposentados, por não terem mais a rotina diária de trabalho, dispõem de mais tempo livre para se dedicarem aos mecanismos de controle social.

Entre os conselheiros pesquisados, $21(29,6 \%)$ têm renda de três a cinco salários mínimos, mesma proporção de participantes que apresentam renda de cinco até dez salários mínimos. Na sequência, $18(25,4 \%)$ dos sujeitos pesquisados declararam renda acima de um e meio até três salários mínimos. Os conselheiros sem renda e com renda superior a dez salários mínimos representam, respectivamente, dois $(2,8 \%)$ e cinco $(7 \%)$ participantes.

Portanto, em sua maioria, os CLS possuem renda acima de três salários mínimos, o que representa que os mesmos têm uma certa segurança no que diz respeito a sua subsistência e de sua família. Esta segurança, segundo Tonella (2003), possibilita que o sujeito tenha mais possibilidades de participação, ou seja, fazer parte de uma elite decisória com acesso a maiores níveis de educação, informação, salário e capacitação.

Dentre os conselheiros com renda igual ou superior a três salários mínimos, observa-se que 33 eram mulheres e 14 eram homens. Ou seja, mulheres possuem maior renda do que os homens, fato possivelmente relacionado com a escolaridade, a qual também foi maior entre as mulheres.

Por fim, entre os conselheiros pesquisados, 38 (53,5\%) não possuem plano de saúde, e $33(46,5 \%)$ têm plano de saúde. Desta forma, entende- se que a maioria dos participantes da pesquisa são usuários do SUS, o que implica em melhor reconhecer as necessidades e as demandas colocadas aos serviços de saúde.

\section{Os CLS e o exercício do controle social}

Dos CLS respondentes, 49 (74,2\%) se declararam representantes dos usuários, 11 (16,7\%) do governo e seis $(9,1 \%)$ dos prestadores de serviços e profissionais de saúde. Cinco participantes não informaram

\begin{tabular}{lllll}
\hline Hygeia Uberlândia - MG $\quad$ Edição especial: X GeoSaude & Fev./2022 & p. 12-22 & Página 15
\end{tabular}


seu segmento no conselho local de saúde. Considerando os 49 CLS representantes dos usuários, sete alegaram que já tiveram alguma vivência profissional na área da saúde. Enquanto seis dos nove representantes do governo relataram essa vivência.

Entende-se que a vivência profissional na área da saúde dos conselheiros contribui com os debates e também na elaboração de propostas mais assertivas, à medida que os mesmos conhecem as rotinas dos serviços de saúde. Nahra (2006) aponta que é baixo o número de conselheiros que o são por desejarem ou por entenderem que detêm um conhecimento que os qualifique para a função, na sua maioria estão por acreditarem possuir uma compreensão política do SUS e entender a importância da participação popular.

A rotatividade dos conselheiros reflete no envolvimento e na renovação dos atores sociais envolvidos nos processos decisórios dos mecanismos de participação popular garantidos pelas políticas públicas brasileiras. Segundo Cohn (2003) a baixa rotatividade pode ser atribuída a uma insuficiência do exercício democrático nos conselhos. Com relação ao tempo de participação no conselho local de saúde, quatro (5,6\%) CLS atuam a menos de um ano, 41 (57,7\%) possuem entre um e quatro anos de atuação e $26(36,6 \%)$ possuem mais de quatro anos de atuação. A partir desses dados, percebe-se que há certa rotatividade nos conselhos locais de saúde de Joinville.

Quanto a carga horária destinada pelos conselheiros para as atividades específicas dos conselhos locais. A maioria dos CLS $(n=41,57,7 \%)$ dedica de uma a duas horas semanais ao conselho, 19 $(26,8 \%)$ dedicam menos de uma hora semanal, oito $(11,3 \%)$ dedicam de duas a três horas. Apenas três $(4,2 \%)$ respondentes informaram dedicar mais de três horas semanais para as atividades relacionadas ao conselho. Estudos nacionais sobre trabalho voluntário em outros contextos sociais, apresentam indicam que os voluntários dedicam de uma hora até quatros horas e meia por semana a essas atividades (MILLANI FILHO, 2005; CONSELHO BRASILEIRO DE VOLUNTARIADO EMPRESARIAL, 2016). Portanto, o tempo de dedicação dos CLS está de acordo com as médias de outros setores.

Em relação às possíveis dificuldades que os conselheiros poderiam enfrentar para a participação nas reuniões do conselho local de saúde de Joinville, 54 (76,1\%) dizem não ter nenhuma dificuldade e 17 $(23,9 \%)$ afirmam ter alguma dificuldade em frequentar as reuniões. As dificuldades citadas pelos participantes para participar das reuniões foram: os horários fixos, pois as reuniões são sempre noturnas; motivos pessoais, tais como cuidados com os filhos ou adoecimento; condição adversa ligada à pandemia de Covid-19, por exemplo, dificuldade para acessar os links de reuniões on-line.

Um estudo realizado por Ventura et al. (2017), em Botucatu/SP, revela que a facilidade em participar das reuniões é um fator positivo uma vez que a falta de quórum gera incômodos nos conselheiros que frequentam e que se comprometem com as reuniões do Conselho. Para os autores, aqueles que reservam tempo e disposição para se dedicarem ao controle social são, infelizmente, prejudicados por outros membros que não assumem tal responsabilidade com o cargo, ocasionando conflitos e a falta de uma possível motivação futura em frequentar as reuniões.

Em relação ao apoio para participar dos conselheiros e nas ações desenvolvidas pelos conselhos locais de saúde de Joinville, 57 (80\%) dos pesquisados apontam não receber nenhum tipo de apoio. Nove $(12,7 \%)$ afirmaram que o apoio recebido é a dispensa nas horas de trabalho sem precisar de compensação, três $(4,2 \%)$ recebem liberação de horas no trabalho, mas necessitam compensar e dois $(2,8 \%)$ apontam que são remunerados pelas horas que se dedicam aos trabalhos referentes ao conselho local de saúde ou recebem banco de horas para participar das reuniões.

Destaca-se que a Resolução no 453/2012, do Conselho Nacional de Saúde, que trata das diretrizes para instituição, reformulação, reestruturação e funcionamento dos Conselhos de Saúde, dispõe que a função de membro do Conselho de Saúde não será remunerada, mas considerando a relevância pública da atuação, garante a dispensa do trabalho sem prejuízo para o conselheiro mediante comprovação das atividades exercidas (BRASIL, 2012).

\begin{tabular}{lllll}
\hline Hygeia Uberlândia - MG $\quad$ Edição especial: X GeoSaude & Fev./2022 & p. 12-22 & Página 16
\end{tabular}


Indagou-se se os CLS estão vinculados a um partido político, organizações comunitárias e sindicais e em outros conselhos de políticas públicas. A maior parte dos CLS ( $n=55,77,5 \%)$ dos conselheiros apontam não ter vinculação partidária, participam de organizações comunitárias e sindicais $(n=44$, $62 \%)$. Com relação aos outros conselhos de políticas públicas, 25 (35,2\%) pontuaram que participam.

Estudo de Lemos et al. (2016), realizado em Anápolis/GO, com 177 conselheiros municipais de saúde, indicou que, aproximadamente, $55 \%$ eram filiados a um partido político, um número consideravelmente maior que em Joinville. A participação dos CLS em organizações comunitárias, sindicais e em outros conselhos de políticas públicas entende-se como importante porque cria vínculos com uma base onde podem compartilhar e fortalecer os debates sobre as questões que envolvem as demandas de saúde, bem como buscar ideias e soluções.

Considerando as atribuições elencadas no Regimento Interno dos Conselhos Locais de Saúde de Joinville (JOINVILLE, 2005), os CLS foram perguntados sobre qual tem exercido. A atribuição mais apontada foi a fiscalização e acompanhamento das ações e serviços de saúde $(n=30,42,8 \%)$. Em segundo lugar, ficou a estimulação da participação comunitária no controle, manutenção e desenvolvimento das ações e serviços da saúde no município $(n=17,23,9 \%)$. A tomada de providências para permanente orientação aos usuários sobre os serviços oferecidos nas unidades de saúde foi indicada por 8 CLS $(11,26 \%)$ e o acompanhamento da elaboração do plano de trabalho das unidades de saúde por 7 CLS $(9,85 \%)$. A proposição de medidas de aperfeiçoamento da organização e do funcionamento do centro de saúde e a criação de mecanismos de ouvidoria que permitem que a população dê suas sugestões, tais como urnas e caixas de sugestões, foram apontadas, respectivamente, por $4(5,63 \%)$ e $2(2,81 \%)$ CLS. Sendo que $3(4,22 \%)$ CLS indicaram realizar outras atividades.

Referente à importância da participação nos conselhos locais de saúde, 52 (73,2\%) CLS consideram que é importante a sua participação e $18(25,4 \%)$ afirmam que a ideia de participar do conselho é gratificante. Para Lima (2011), o primeiro passo que os conselheiros devem se atentar antes de iniciar suas atividades com a comunidade é a compreensão da própria equipe que o processo em si é importante, já que um dos maiores entraves ao bom resultado e ao bom funcionamento do conselho local de saúde é a própria equipe.

No quesito da definição de pautas desenvolvidas e abordadas no conselho local de saúde, a 52 $(73,23 \%)$ CLS afirmaram participar sempre ou frequentemente. O que demostra um engajamento desses membros e maior possibilidade de melhorar a saúde pública. Lavôr et al. (2017, p. 81) destacam que: "Deve-se garantir e ir à busca da participação dos usuários nas reuniões do conselho, procurando estimulá-los, usando de métodos diversos, já que é comum da comunidade achar que ela não tem o dever de ajudar a solucionar os problemas".

Buscou-se compreender como é realizada a dinâmica da atuação dos CLS. Nesse sentido, quanto a forma de discussão de pautas, $41(57,7 \%)$ dos CLS relatam que é realizada por reuniões com os responsáveis pela entidade, $16(22,5 \%)$ apontaram que as discussões das pautas são realizadas durante as reuniões plenárias da entidade e $14(19,7 \%)$ dizem que as discussões das pautas são realizadas durante as assembleias. Busana, Heidemann e Wendhausen (2015) afirmam que realizar um tempo de instrução durante as reuniões para colaborar com o empoderamento dos conselheiros é uma estratégia utilizada nos conselhos. Entende-se, então, que a melhor forma de estar por dentro de todos os assuntos discutidos é ter uma participação mais efetiva nas reuniões e assembleias do conselho de saúde, pois é através delas que a maioria dos assuntos são discutidos.

Dentre os CLS participantes, 56 (78,8\%) acreditam o Conselho Municipal de Saúde (CMS) de Joinville oferece grande ou muito grande contribuição para o fortalecimento dos conselhos locais. Outros, 15 $(18,3 \%)$ afirmaram ser pequena e $2(2,8 \%)$ consideraram ser muito pequena. Portanto, entende-se que há uma parceria entre os conselhos locais de saúde e o CMS.

Em relação aos desafios para melhorar o funcionamento do CMS de Joinville, os conselheiros apontam que precisa melhorar: a interlocução com a sociedade $(n=19,26,8 \%)$, a participação dos conselheiros

Hygeia Uberlândia - MG $\quad$ Edição especial: X GeoSaude $\quad$ Fev./2022 p. 12-22 Página 17


$(n=12,16,9 \%)$, a representatividade das entidades e dos conselheiros $(n=11,15,5 \%)$, a organização e planejamento $(n=10,14,1 \%)$, a relação com o poder público $(n=8,11,3 \%)$, a capacitação dos conselheiros ( $n=6,8,5 \%)$ e a interação com outros conselhos e entidades $(n=5,7 \%)$. Percebe-se pelas opiniões que precisa haver mais empenho para garantir a representação, a capacitação e a representatividade de todas as partes envolvidas. Ferretti et al. (2016) alertam para a educação permanente junto aos conselheiros de saúde como meio de reflexão sobre temas relevantes e ampliação do entendimento do seu papel e suas atribuições.

Avaliando a comunicação, $64(91,4 \%)$ consideraram muito boa ou boa a comunicação entre os CLS. Enquanto, 61 (87,1\%) apontaram a comunicação entre os CLS e a sociedade civil muito boa ou boa. Para Lima (2011) a comunicação é a base para manter o CLS funcionando, com a possível certeza de que há alguma efetividade dos encaminhamentos que ali surgem. Segundo Araújo (2003), a comunicação molda as atitudes e comportamentos e se efetiva por meio de informação suficiente e adequada. Logo, a boa comunicação facilita as relações interpessoais, a tomada de decisões e a união em prol dos trabalhos realizados nos CLS.

A infraestrutura e o suporte técnico são fundamentais para o bom funcionamento dos CLS. Nesse encaminhamento, a avaliação dos participantes da pesquisa aponta que, em Joinville, para 62 (87,3\%) essa condição é boa ou muito boa. Apenas 9 (12,7\%) CLS afirmaram ser ruim. Dos CLS participantes, $69(97,1 \%)$ consideram que frequentemente ou sempre há o repasse das informações referentes às políticas de saúde do município. Sobre apresentar e discutir o orçamento público com os CLS, 33 $(46,5 \%)$ conselheiros disseram que os orçamentos são apresentados e discutidos, 24 (33,8\%) disseram que isso é feito de maneira parcial e $14(19,7 \%)$ avaliaram que não existe apresentação e discussão.

Por conseguinte, compreende-se que, em grande medida, os conselhos locais têm condições de funcionamento e acesso às informações do município de Joinville. As informações referentes ao orçamento público fortalecem as possibilidades de participação e, consequentemente, da democracia e do exercício da cidadania (SOUZA e KRÜGER, 2010).

O apoio administrativo e a infraestrutura física dos conselhos não apenas dizem respeito às suas condições de funcionamento, mas também são indicadores do apoio político do gestor do SUS ao controle social e à gestão participativa (VAN STRALEN et al., 2006), o que destaca de maneira positiva a SMS de Joinville.

Em geral, as decisões tomadas pelo conselho local de saúde têm respeito dos gestores da saúde de Joinville. Pois, $46(64,7 \%)$ dos CLS participantes avaliaram que frequentemente ou sempre as decisões do conselho são acatadas e respeitadas. No entanto, percebe-se que ainda existem dificuldades para que o executivo acate suas decisões, tendo em vista que a opção "às vezes", obteve $22(31 \%)$ respostas e outros 3 CLS $(4,2 \%)$ consideraram que as decisões nunca ou raramente são acatadas ou respeitadas.

Souza e Krüger (2010) evidenciam o conselho local de saúde como o espaço de participação mais próximo da comunidade, onde primeiro as necessidades dos usuários podem se manifestar. Nesse sentido, tem o potencial de se articular com os outros níveis de participação que são deliberativos da política de saúde, realizando uma possível aproximação com a democracia direta e uma democracia representativa vinculada às suas bases sociais. Esse potencial, quando reconhecidos pelos gestores municipais, fortalecem o SUS e agregam confiança entre os mecanismos de controle social e a prefeitura municipal.

Quando questionados sobre quais temas sentem necessidade de aprimoramento e capacitação para que consigam exercer melhor suas atividades, dentre as opções do questionário, os conselheiros sinalizaram que precisam saber mais sobre: o seu papel como conselheiro $(n=24,33,8 \%)$, transparência pública $(n=20,28,2 \%)$, orçamento público $(n=9,12,7 \%)$, controle social $(n=6,8,5 \%)$, papel do ministério público $(n=5,7 \%)$, democracia participativa $(n=3,4,2 \%)$, estrutura do estado ou governo $(n=2,2,8 \%)$ e negociação de conflitos $(n=1,1,4 \%)$ e todos $(n=1,1,4 \%)$.

\begin{tabular}{lllll}
\hline Hygeia Uberlândia - MG $\quad$ Edição especial: X GeoSaude & Fev./2022 & p. 12-22 & Página 18
\end{tabular}


Nesse encaminhamento, desde a 12ำ Conferência Nacional de Saúde, em 2003, são discutidas propostas e a necessidade de se garantir recursos para o investimento da capacitação dos conselheiros de saúde em todas as suas instâncias. Acredita-se que, o investimento em formação continuada para os que se propõe compor os mecanismos de controle social fortalece a autonomia e o empoderamento dos representantes. Dessa maneira, é essencial "incentivar a formação e estruturação dos Conselhos Locais de Saúde, apoiar e dinamizar suas ações, viabilizando a participação dos Conselhos Locais em Conferências, Fóruns de Saúde e outros eventos semelhantes" (BRASIL, 2003, p. 103). A garantia da participação popular nos CLS bem como nos demais conselhos inclui, também, o comprometimento dos gestores da saúde planejar e viabilizar espaços de capacitação como palestras, oficinas e participação em eventos. Quanto mais capacitados mais condições do exercício do controle social conforme prevê o SUS.

\section{CONSIDERAÇÕES FINAIS}

No desenvolvimento da pesquisa encontrou-se alguns desafios para a coleta de dados no que resultou na participação de apenas 71 conselheiros de um total de 264. No contexto da pandemia de Covid-19, em decorrência da necessidade de distanciamento social, as reuniões presenciais dos conselhos locais de saúde foram canceladas em março de 2020. E, não se teve uma iniciativa dos mesmos para que houvesse reuniões online. Os espaços das reuniões seriam importantes para que os pesquisadores pudessem apresentar o projeto de pesquisa e sensibilizar para que todos participassem da pesquisa. Além disso, facilitaria para os presidentes divulgarem a pesquisa e se mobilizarem para a adesão.

Um outro desafio foi o acesso aos contatos dos CLS para envio do link do questionário, pois foi disponibilizado pela SMS de Joinville somente o contato dos presidentes dos conselhos locais. Acredita-se que, por não terem tanta familiaridade com as ferramentas da internet, houve certa dificuldade entre os CLS de compartilhar a pesquisa com os pares.

Os resultados apontam para a valorização dos conselhos locais de saúde como espaço de controle social pelos CLS de Joinville, os quais entendem a sua intervenção como relevante para a efetivação do SUS. A avaliação positiva dos respondentes quanto ao apoio e à transparência do município no que diz respeito ao apoio técnico, à infraestrutura e ao acesso às informações necessárias para a efetivação da participação e do controle social é outro fator a ser destacado.

A relação com o CMS também foi vista pelos sujeitos da pesquisa como favorável para o fortalecimento do controle social do SUS em Joinville. Isso se dá, principalmente pela abertura de espaços, boa comunicação e valorização de cada instância na mesma proporção. O diálogo entre os conselhos é sinalizado como fundamental para que cada vez mais esses espaços sejam democráticos e favoráveis ao exercício da cidadania.

A partir deste estudo, espera-se que os conselhos e a Secretaria Municipal de Saúde possam se apropriar desses indicadores para planejar suas ações e, dessa maneira, contribuir para o fortalecimento do controle social do Sistema Único de Saúde no município de Joinville.

Sugere-se, ainda, que outros estudos possam complementar os dados apresentados nesse trabalho, utilizando-se de outros instrumentos de coleta de dados, como a entrevista em profundidade, e com a possibilidade de ida a campo pelos pesquisadores. Além disso, pode-se investir em uma pesquisa para a definição do perfil dos conselheiros municipais de saúde e, posteriormente, verificar se são semelhantes ou não presentes achados.

\section{AGRADECIMENTOS}

Esta pesquisa foi aprovada no Edital 23/2019/PROPPI/DAE do IFSC e contou com recursos financeiros para quatro bolsas de pesquisa as quais foram destinadas à acadêmicos de Gestão Hospitalar que colaboraram na coleta de dados. 


\section{REFERÊNCIAS}

BELTRÃO, K.I.; ALVES, J.E.D. A Reversão do Hiato de Gênero na Educação Brasileira no Século XX. Cadernos de Pesquisa, v.39, n.136, p.125-156, jan./abr. 2009. Disponível em: https://www.scielo.br/pdf/cp/v39n136/a0739136.pdf. Acesso em: 29 mai. 2021. https://doi.org/10.1590/S0100-15742009000100007

BRASIL. Lei no 8080, 19 de setembro de 1990. Dispõe sobre as condições para a promoção, proteção e recuperação da saúde, a organização e o funcionamento dos serviços correspondentes e dá outras providências. Brasília: Presidência da República, 1990. Disponível em: http://www.planalto.gov.br/ccivil 03/leis//8080.htm. Acesso em: 28 abr. 2020.

Ministério da Saúde. Conselho Nacional de Saúde. 12a Conferência Nacional de Saúde: relatório final. Brasília, 2003. 230 p. Disponível em: https://conselho.saude.gov.br/biblioteca/Relatorios/relatorio 12.pdf. Acesso em: 14 fev. 2021.

. Ministério da Saúde. Conselho Nacional de Saúde. Resolução no 453, de 10 de maio de 2012. Disponível em: https://bvsms.saude.gov.br/bvs/saudelegis/cns/2012/res0453 1005 2012.html. Acesso em: 05 nov. 2021.

Ministério da Saúde. Para entender o controle social na saúde. Brasília: Ministério da Saúde, 2013. 178 p. Disponível em: https://conselho.saude.gov.br/biblioteca/livros/Manual Para Entender Controle Social.pdf. Acesso em: 10 mar. 2020.

BUSANA, J. de A.; HEIDEMANN, I.T.S.B.; WENDHAUSEN, A.L.P. Popular participation in a local health council: limits and potentials. Texto \& Contexto - Enfermagem, v. 24, n. 2, p. 442-449, jun. 2015. Disponível em: https://www.scielo.br/pdf/tce/v24n2/pt 0104-0707-tce-24-02-00442.pdf. Acesso em: 11 fev. 2021. https://doi.org/10.1590/0104-07072015000702014

CEZARE, J.P. Conselhos municipais e governança: uma análise do Conselho de Representantes de Paranapiacaba e Parque Andreense do Município de Santo André - SP. 2009. Dissertação (Mestrado em Saúde Pública) - Faculdade de Saúde Pública da Universidade de São Paulo, São Paulo. Disponível em: https://www.teses.usp.br/teses/disponiveis/6/6134/tde21092009-152457/pt-br.php. Acesso em: 29 mai. 2021.

COHN, A. Estado e sociedade e as reconfigurações do direito à saúde. Ciência \& Saúde Coletiva, v. 8, n. 1, p. 09-18, 2003. Disponível em: https://www.scielo.br/scielo.php?script=sci arttext\&pid=S141381232003000100002\&lng=pt\&tlng=pt. Acesso em: 13 jan. 2021. https://doi.org/10.1590/S1413-81232003000100002

CONSELHO BRASILEIRO DE VOLUNTARIADO EMPRESARIAL. Censo CBVE: 2016. Rio de Janeiro: CBVE, 2016. 30 p. Disponível em: http://www.cbve.org.br/wp-content/uploads/RelatorioCenso-CBVE-2016.pdf. Acesso em: 09 fev. 2021.

DEGENSZAJN, R.R. Democratizar a Gestão das Políticas Sociais: Um Desafio a Ser Enfrentado pela Sociedade Civil. In: MOTA, A.E.; BRAVO, M.I.; UCHÔA, R.; NOGUEIRA, V.M.; MARSIGLIA, R.; GOMES, L.; TEIXEIRA, M. Serviço Social e Saúde: formação e trabalho profissional. 4. ed. São Paulo: Cortez, 2013. Cap. 14. p. 73-87. Disponível em: http://www.poteresocial.com.br/livro-servicosocial-e-saude-para-download/. Acesso em: 10 mar. 2020.

FERRETTI, F. et al. Participação da comunidade na gestão e controle social da política de saúde. Tempus - Actas de saúde coletiva, Brasília, v. 3, n. 10, p.51-67, set. 2016. Disponível em: http://www.tempusactas.unb.br/index.php/tempus/article/view/1777/16. Acesso em: 17 mar. 2020. https://doi.org/10.18569/tempus.v10i3.1777

IBGE. Instituto Brasileiro de Geografia e Estatística. Cidades@: Joinville. Disponível em: https://cidades.ibge.gov.br/brasil/sc/joinville/panorama. Acesso em: 29 mai. 2020.

\begin{tabular}{lllll}
\hline Hygeia Uberlândia - MG $\quad$ Edição especial: X GeoSaude & Fev./2022 & p. 12-22 & Página 20
\end{tabular}


JOINVILLE. Secretaria da Saúde. Conselho Municipal de Saúde. Resolução 29, de 09 de maio de 2005. Regimento Interno dos Conselhos Locais De Saúde de Joinville. Joinville: Prefeitura Municipal, 2005. Disponível em:

http://www1.tce.rs.gov.br/portal/pls/portal/PORTAL.wwsbr imt services.GenericView?p docname=11 61430.PDF\&p type=DOC\&p viewservice=VAHWSTH\&p searchstring $=$. Acesso em: 14 de jan. 2021.

LAVÔR, T.B. de S.L. et al. A percepção de profissionais de saúde sobre o controle social no município de Teresina/PI. Brazilian Journal of Surgery and Clinical Research, Cianorte, v. 19, n. 1, p. 81-86, ago. 2017. Disponível em:

https://www.mastereditora.com.br/periodico/20170605 152719.pdf. Acesso em: 10 fev. 2021.

LEMOS, C.L.S. et al. Perfil e visão dos conselheiros municipais de saúde sobre sua atuação. Gestão \& Saúde, Brasília, v. 7, n. 3, p. 1126-1139, set. 2016. Disponível em:

https://periodicos.unb.br/index.php/rgs/article/view/3615/3295. Acesso em: 28 abr. 2020.

https://doi.org/10.18673/gs.v7i3.21985

LIMA, M.C. A Estratégia de Saúde da Família e a Organização dos Conselhos Locais de Saúde: Exercitando o 2ำ princípio. Pirassununga: Lawbook, 2011. 92 p.

MILLANI FILHO, M. A. F. Estimativa e Contabilização do Trabalho Voluntário em Organizações Filantrópicas. Anais [...]. Congresso Internacional de Custos, IX, Florianópolis, 28 a 30 de novembro de 2005. Disponível em: https://anaiscbc.emnuvens.com.br/anais/article/view/1935. Acesso em: 5 nov. 2021.

NAHRA, C.M.L. Conselhos Municipais - Potencializando a Gestão Participativa: a representação do executivo municipal nos conselhos gestores de políticas públicas. Porto Alegre: Secretaria Municipal de Coordenação Política e Governança Local, 2006. 25 p. Disponível em:

http://lproweb.procempa.com.br/pmpa/prefpoa/observatorio/usu doc/executivo conselhos.pdf. Acesso em: 09 fev. 2021.

PEDRINI, D.M.; ADAMS, T.; SILVA, V.R. Controle social de políticas públicas: caminhos descobertas e desafios. São Paulo: Paulus, 2007. 237 p.

RAMOS, M. de F. et al. Conselhos Setoriais: perfil dos conselheiros e sua influência na tomada de decisão. Saúde Soc., São Paulo, v.21, supl.3, p.61-70, 2012. Disponível em:

https://www.scielosp.org/pdf/sausoc/2012.v21suppl3/61-70/pt. Acesso em: 29 mai. 2021.

https://doi.org/10.1590/S0104-12902012000700006

SOUZA, A.V. de; KRÜGER, T.R. Participação Social no SUS: proposições das conferências sobre o conselho local de saúde. Revista de Saúde Pública de Santa Catarina, Florianópolis, v. 3, n. 1, p. 80-96, 2010. Disponível em: http://revista.saude.sc.gov.br/inicio/article/view/72. Acesso em: 01 fev. 2021.

SOUZA, C.R.; BARROS, R. S. de; OLIVEIRA, M.A. de. Conselhos Municipais de Saúde de Osasco e Região: identificação de perfil, controle social e formulação de políticas para o SUS. BIS, Boletim do Instituto de Saúde, n. 43, p. 29-31, 31 dez. 2007. Acesso em: 01 fev. 2021. Disponível em: https://periodicos.saude.sp.gov.br/index.php/bis/article/view/33597. Acesso em: 01 fev. 2021.

TONELLA, Celene. Conselhos municipais de políticas públicas: participação e governança local. XI Congresso Brasileiro de Sociologia, 1 a 5 de setembro de 2003, Unicamp, Campinas, SP. In: Anais do XI Congresso Brasileiro de Sociologia. Porto Alegre: Sociedade Brasileira de Sociologia, 2003. Disponível em: http://www.sbsociologia.com.br/portal/index.php?option=com docman\&task=cat view\&gid=107\&limit= 50\&limitstart=0\&order=name\&dir=ASC\&ltemid $=170$. Acesso em: 29 mai. 2021

VAN STRALEN, C.J. et al. Conselhos de Saúde: efetividade do controle social em municípios de Goiás e Mato Grosso do Sul. Ciência \& Saúde Coletiva, v. 11, n. 3, p. 621-632, set. 2006. Disponível

\begin{tabular}{|c|c|c|c|}
\hline & Uberlândia - MG & Edição especial: X GeoSaude & Fev $/ 2$ \\
\hline
\end{tabular}


em: http://www.scielo.br/scielo.php?script=sci arttext\&pid=S1413-81232006000300011. Acesso em: 31 mar. 2020. https://doi.org/10.1590/S1413-81232006000300011

VENTURA, C.A.A. et al. Cultura participativa: um processo de construção de cidadania no Brasil. Interface [online], v. 21, n. 63, p. 907-920, out./dez. 2017. Disponível em:

https://doi.org/10.1590/1807-57622015.0941. Acesso em: 05 nov. 2021. https://doi.org/10.1590/1807$\underline{57622015.0941}$

WOLLSTONECRAFT, M. Reivindicação dos direitos da mulher. São Paulo: Boitempo, 2016,256 p. Disponível em: https://www2.boitempoeditorial.com.br/produto/reivindicacao-dos-direitos-da-mulher-554. Acesso em: 07 jan. 2021. 